\title{
Crystallization of Poly(ethylene terephthalate) from Oriented Amorphous Film
}

\author{
Dedicated to the Memory of the late Professor Ichiro Sakurada
}

Renyuan QIAN, Jiasong HE, and Deyan SHEN

Institute of Chemistry, Academia Sinica, Beijing, P.R. China

(Received January 10, 1987)

\begin{abstract}
Solution cast amorphous poly(ethylene terephthalate) (PET) films were hot drawn uni-axially at $80-130 \% \mathrm{~min}^{-1}$ to a draw ratio of $4-5$ at $85-94{ }^{\circ} \mathrm{C}$ to give amorphous films of high chain orientation in the global sense while the segmental orientation was entirely random. These films were isothermally crystallized at $110^{\circ} \mathrm{C}$ with film ends clamped tight. The kinetics of crystallization was followed by FTIR based on a computer resolution of the $1020 \mathrm{~cm}^{-1}$ band into trans-conformations in crystalline and in amorphous regions and gauche conformation. An induction period of 5-6 min was observed for the crystallization of the oriented film, while undrawn film did not show an induction period longer than $45 \mathrm{~s}$. Comparison with stress relaxation data of these oriented amorphous films at $82-112^{\circ} \mathrm{C}$ indicates that the thermal relaxation of the global chain orientation by dis-entanglement and rubbery flow which precedes crystallization is responsible for the induction period.
\end{abstract}

KEY WORDS Crystallization Kinetics / Poly(ethylene terephthalate) /

Uni-axially Drawn Film / Stress Relaxation /

When an amorphous poly(ethylene terephthalate) (PET) film is drawn above its glass transition temperature $\left(T_{\mathrm{g}}\right)$ the film will undergo strain-induced crystallization or not depending on the drawing rate and temperature as a consequence of the rivalling processes of chain orientation and its thermal relaxation., ${ }^{1,2}$ By drawing at lower rates to a certain draw ratio in the temperature range of $80-105^{\circ} \mathrm{C}$ the drawn film may appear amorphous by wide angle X-ray diffraction (WAXD), dynamic mechanical spectrometry (DMS) and the chain segments remain unoriented as judged from results of WAXD, infra-red dichroism, sound velocity and optical birefringence measurements. ${ }^{3-7}$ However, in such hot drawn amorphous PET films the macromolecular chains are in fact highly oriented in the global sense, which is shown by thermal shrinkage, anisotropy in thermal conductivity and elongational stressstrain behavior and also by scanning electron microscopy (SEM). ${ }^{7}$ The term of oriented amorphous film is suggested by the authors ${ }^{7}$ to describe such drawn amorphous PET film, where the molecular chains in global sense are highly oriented while the local segments have random orientation as a result of the enormous difference in the relaxation times of chain segments and global chains. In the present paper the effect of such global chain orientation on the thermal crystallization of the oriented amorphous PET film is studied by Fourier transform infra-red spectrometry (FTIR) in an attempt to elucidate the detailed processes involved. 
The methods commonly used to study crystallization rate of polymers include density, microscopy, X-ray diffraction, differential scanning calorimetry (DSC), depolarized light intensity etc. However, fast crystallization process can not be followed by most of the methods mentioned. For the investigation of the isothermal crystallization of oriented amorphous PET films fast response to the process is necessary and thermal shrinkage of the specimen during crystallization is to be avoided. Shen et al. ${ }^{8,9}$ found that the IR band near $1020 \mathrm{~cm}^{-1}$ assigned to the in-plane bending vibration mode of phenyl $\mathrm{C}-\mathrm{H}$ in $\mathrm{PET}$ is a band sensitive to the conformation of the $-\mathrm{O}-\mathrm{CH}_{2} \mathrm{CH}_{2}-\mathrm{O}-$ moiety in the chain and the bands at $1024,1021.5$ and $1018 \mathrm{~cm}^{-1}$ have been assigned to trans in the crystalline region $\left(T_{\mathrm{c}}\right)$, trans in the amorphous region $\left(T_{\mathrm{a}}\right)$, and gauche $(G)$ conformations respectively. The origin of the effect of $-\mathrm{O}-\mathrm{CH}_{2}-\mathrm{CH}_{2} \mathrm{O}-$ conformation on the in-plane bending frequency of phenyl $\mathrm{C}-\mathrm{H}$ is not clear at present, very probably in the amorphous region two carboxyl groups of the terephthalate being non-coplanar. The relative contents of $T_{\mathrm{c}}, T_{\mathrm{a}}$, and $G$ can thus be directly obtained by means of computer resolution of these overlapping bands of the IR spectrum of PET film between 1040 and $990 \mathrm{~cm}^{-1}$. This analysis of the $1020 \mathrm{~cm}^{-1}$ band was used in the following isothermal crystallization of oriented amorphous PET films.

\section{EXPERIMENTAL}

Air-quenched melt-extruded PET films of $1 \mathrm{~mm}$ thickness were amorphous and isotropic by WAXD, birefringence and DMS measurements. Viscosity average mol mass was $1.63 \times 10^{4}$. Its $T_{\mathrm{g}}$ was $76^{\circ} \mathrm{C}$ as determined by DMS $\left(3.3 \mathrm{~Hz}, 2 \mathrm{~K} \cdot \mathrm{min}^{-1}\right)$ and by DSC (20 $\mathrm{K} \mathrm{min}^{-1}$ ). The half-time of crystallization at 229 and $119^{\circ} \mathrm{C}$ determined by depolarized light intensity method ${ }^{10}$ were 5.3 and $4.5 \mathrm{~min}$, respectively.
Hot drawing of amorphous PET films was performed uni-axially with the other direction free to contract on a laboratory stretching setup constructed in this laboratory. After drawing the films were quenched to room temperature by air immediately. Stress relaxation of the stretched amorphous films was measured on the same machine at various temperatures between 82 and $112^{\circ} \mathrm{C}$. A Si semiconductor transducer was used to read the force. During stretching an increase of specimen temperature amounting to $2-3^{\circ} \mathrm{C}$ was observed due to heat developed in the specimen.

DMS in the draw direction of the specimen was conducted at $3.3 \mathrm{~Hz}$ on an Iwamoto Viscoelastic Spectrometer with a servocontrolled pre-stress at a heating rate of $2 \mathrm{Kmin}^{-1}$. Dynamic mechanical loss tangent, $\operatorname{tg} \delta$, values were recorded during the first temperature scan from room temperature to $130^{\circ} \mathrm{C}$.

Thermal shrinkage of drawn PET films was determined by immersing strip specimen in hot water at $80^{\circ} \mathrm{C}$ for $1 \mathrm{~h}$. The recovery of deformation $R$ was calculated according to

$$
R=\frac{l_{1}-l_{2}}{l_{1}-l_{1} / \lambda} \times 100 \%
$$

where $l_{1}, l_{2}$ are lengths of the specimen before and after hot water treatment, respectively, and $\lambda$ is the draw ratio.

Isothermal crystallization of amorphous PET films was measured by FTIR on a Bruker Model IFS-113 V spectrometer with a cumulation of 30 scans in approximately $45 \mathrm{~s}$. The amorphous PET films used were cast from $2.5 \%$ solution of PET in chloroformtrifluoroacetic acid $(9: 1 \mathrm{v} / \mathrm{v})$ at $60-70^{\circ} \mathrm{C}$. Some of the films were uni-axially drawn to $\lambda$ $4-5$ at a draw rate of $80-130 \% \mathrm{~min}^{-1}$ in the temperature range of $85-94^{\circ} \mathrm{C}$ to get the oriented amorphous films. The oriented amorphous film was fixed at both ends on a metal frame tightly to prevent the film from shrinkage during crystallization, while the undrawn amorphous film was held between two 
Table I. Parameters for the re-construction of IR spectrum in $990-1040 \mathrm{~cm}^{-1}$ region

\begin{tabular}{lrcc}
\hline & $T_{\mathrm{c}}$ & $T_{\mathrm{a}}$ & $G$ \\
\hline Band position $/ \mathrm{cm}^{-1}$ & 1024.2 & 1021.5 & 1017.8 \\
Band width $/ \mathrm{cm}^{-1}$ & 5.4 & 6.4 & 6.8 \\
Relative absorptivity & 2.26 & 1.91 & 1 \\
\hline
\end{tabular}

pieces of cardboard so that the film could contract freely during crystallization at elevated temperatures. The samples under crystallization were kept in an oven at desired temperatures. IR band resolution to obtain the relative content of $T_{\mathrm{c}}, T_{\mathrm{a}}$, and $G$ was based on the computer simulation of the spectrum between 1040 and $990 \mathrm{~cm}^{-1}$ with regression analysis, assuming the band shape fits a mixed Lorentz-Gaussian function (8:2). Absorption peak positions, widths and relative absorptivities of the three bands (Table I) were evaluated from solution cast films on $\mathrm{NaCl}$ plates annealled at $95,125,140,160,180,200$, 220,230 , and $240^{\circ} \mathrm{C}$ to give different crystallinities. ${ }^{8}$ Another band appearing in the spectrum region peaked at $1043 \mathrm{~cm}^{-1}$ with a band width of $24 \mathrm{~cm}^{-1}$ was taken into account during the reconstruction of the spectrum.

\section{RESULTS AND DISCUSSION}

\section{Isothermal Crystallization}

Relative contents of $T_{\mathrm{c}}, T_{\mathrm{a}}$, and $G$ conformations of undrawn and oriented amorphous PET films measured at room temperature are shown in Table II. It is interesting to note that $T_{\mathrm{c}}$ in the oriented amorphous film, $0.3 \%$, is even smaller than the value $1.5 \%$ found in the undrawn film. This is in accord, however, with the finding that the dynamic mechanical $\operatorname{tg} \delta_{\max }$ arround $T_{\mathrm{g}}$ of the former is higher than that of the latter. ${ }^{7} T_{\mathrm{a}}$ in the oriented amorphous film, $5.3 \%$, is much larger than that in the undrawn film, $0.4 \%$. This indicates a disruption of crystalline region and a $G$ to $T_{\mathrm{a}}$ conformational
Table II. Conformation break down in PET films, \% content

\begin{tabular}{lccc}
\hline & $T_{\mathrm{c}}$ & $T_{\mathrm{a}}$ & $G$ \\
\hline Undrawn amorphous film & 1.5 & 0.4 & 98.1 \\
Oriented amorphous film $^{\mathrm{a}}$ & 0.3 & 5.3 & 94.4 \\
\hline
\end{tabular}

a Drawn at $130 \% \min ^{-1}$ to $\lambda=5$ at $86^{\circ} \mathrm{C}$.

change in the amorphous region during hot drawing. The kinetics of $T_{\mathrm{c}}, T_{\mathrm{a}}$, and $G$ conformation changes during isothermal crystallization at $110^{\circ} \mathrm{C}$ for the undrawn and oriented amorphous films are shown in Figrue 1. For the undrawn film the content of $T_{\mathrm{c}}$ increased rapidly as soon as the specimen was put into the oven and the increase levelled off after $30 \mathrm{~min}$, the total increase being $7 \%$. In contrast to this, for the oriented amorphous film $T_{\mathrm{c}}$ content remained less than $0.5 \%$ for $5-6 \mathrm{~min}$ which means an induction period for crystallization. After $6 \mathrm{~min} T_{\mathrm{c}}$ content increased rapidly and levelled off beyond $50 \mathrm{~min}$, the total increase being $6 \%$. At the same time the $T_{\text {a }}$ contents in both films showed a sharp decrease at the start of crystallization and then increased rapidly after $3-5 \mathrm{~min}$, levelling off to a net increase of $c a .14 \%$ from the minimum. Parallel to the decrease of $T_{\mathrm{a}}$ content an increase of $G$ content was observed during the initial stage of crystallization and then decreased rapidly, levelling off to a $G$ content of $c a .77 \%$ in both cases.

Avrami plot has been tried for the crystallization kinetics as shown in Figure 2, in which $X_{\mathrm{c}}$ is the crystallinity of the sample at time $t$ and $X_{\infty}$ is that at which further increase of crystallinity with time is imperceptible, and

$$
\frac{X_{\mathrm{c}}}{X_{\infty}}=\frac{C(t)-C(0)}{C(\infty)-C(0)}
$$

where $C(0), C(t)$, and $C(\infty)$ are $T_{\mathrm{c}}$ contents at beginning of crystallization, at time $t$ and at later periods when further increase is imperceptible, respectively. For the undrawn amorphous film the plot is linear with a slope of 2.0 . 


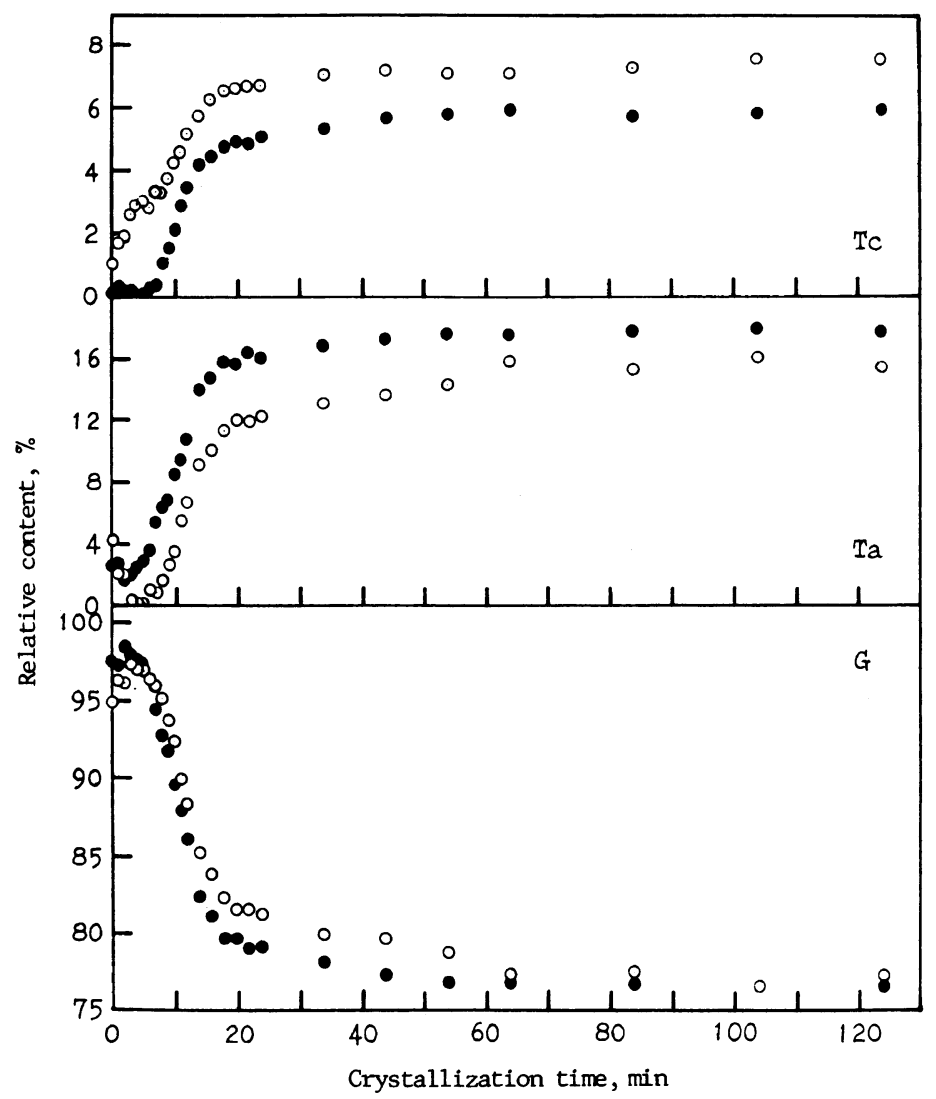

Figure 1. Isothermal crystallization of amorphous PET films at $110^{\circ} \mathrm{C}$. $\bigcirc$, undrawn film; $\bigcirc$, oriented film drawn at $130 \% \min ^{-1}$ to $\lambda=5$ at $86^{\circ} \mathrm{C}$.

For the oriented amorphous film the plot is linear only in the initial stage of crystallization of $8-14 \mathrm{~min}$ with a slope of 3.0. In later times data deviate from the straight line to a much smaller slope.

Thermal Relaxation and the Induction Period of Crystallization

An induction period of 5-6 min exists in the isothermal crystallization of the oriented amorphous PET film at $110^{\circ} \mathrm{C}$. The only difference, which may be responsible to this induction period, between the oriented amorphous film and the undrawn amorphous film is the global chain orientation present in the former. It is natural to suppose that thermal relaxation of the global chain orientation is probably the cause of the crystallization induction period. Thermal stress relaxation experiments were done on oriented amorphous films drawn at $33 \% \mathrm{~min}^{-1}$ to $\lambda=1.7$ and subsequently relaxed at temperatures between 82 and $112^{\circ} \mathrm{C}$. Experimental results are shown in Figure 3. The drawn films relaxed for $1 \times 10^{4} \mathrm{~s}$ were examined by DMS and the position, height and shape of the $\alpha$-peak $\left(T_{\mathrm{g}}\right)$ of the $\operatorname{tg} \delta$ $T$ curve were used as a probe for the state of macromolecular aggregation in the amorphous regions. ${ }^{5}$ For the specimens relaxed at $82-97^{\circ} \mathrm{C}$ sharp and high $\alpha$-peak around $80^{\circ} \mathrm{C}$ was observed which indicates that the specimen remained amorphous after $10^{4} \mathrm{~s}$ relaxation. For the specimen relaxed at $105^{\circ} \mathrm{C}$ a broad and low $\alpha$-peak shifted to $100^{\circ} \mathrm{C}$ was observed 
indicating crystallization during the relaxation experiment. The results are summarized in Table III. In fact there is a minimum in the

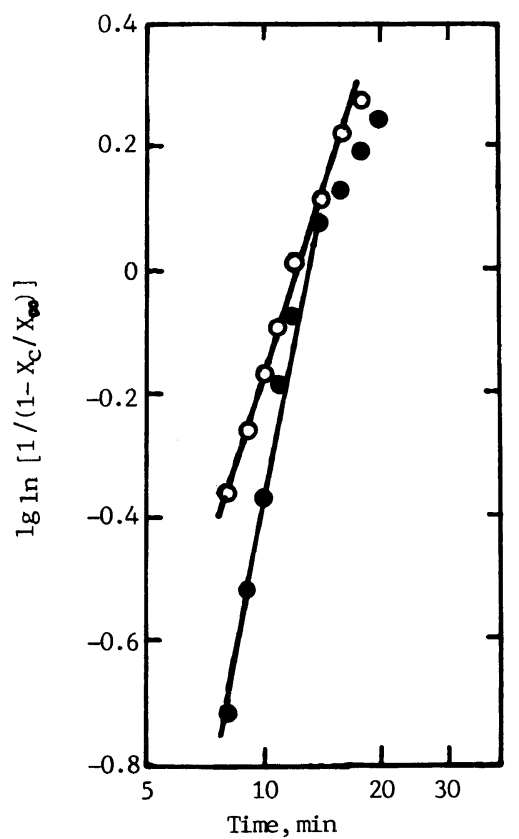

Figure 2. Avrami plots of isothermal crystallization of amorphous PET films at $110^{\circ} \mathrm{C}$. $\bigcirc$, undrawn film; oriented film drawn at $130 \% \min ^{-1}$ to $\lambda=5$ at $86^{\circ} \mathrm{C}$. stress relaxation curve in Figure 3 located around $30 \mathrm{~min}$ then followed by a rise of stress values. For the specimen relaxed at $112^{\circ} \mathrm{C}$ the stress minimum of the stress relaxation curve occurs around $3 \mathrm{~min}$. The stress rise in the relaxation indicates the commencement of crystallization. Comparing these results with the induction period ob-

Table III. DMS data for oriented amorphous PET films after stress relaxation for $10^{4} \mathrm{~s}$. The films has been drawn at $33 \% \mathrm{~min}^{-1}$ to $\lambda=1.7$

\begin{tabular}{cccc}
\hline $\begin{array}{c}\text { Relaxation } \\
\text { temperature/ } \\
{ }^{\circ} \mathrm{C}\end{array}$ & $\operatorname{tg} \delta_{\max }$ & $\begin{array}{c}\text { Peak } \\
\text { temperature/ } \\
{ }^{\circ} \mathrm{C}\end{array}$ & $\begin{array}{c}\text { Peak } \\
\text { half-width/ } \\
{ }^{\circ} \mathrm{C}\end{array}$ \\
\hline 83 & 1.05 & 81 & 10 \\
90 & 0.94 & 80 & 13 \\
97 & 0.74 & 82 & 18 \\
105 & 0.24 & 100 & 48 \\
\hline
\end{tabular}

Table IV. Thermal shrinkage at $80^{\circ} \mathrm{C}, 1 \mathrm{~h}$ for PET films drawn at $30 \% \mathrm{~min}^{-1}$ to $\lambda=1.7$ and relaxed at $96^{\circ} \mathrm{C}$

$\begin{array}{llllll}\text { Time of relaxation/s } & 1 & 10 & 10^{2} & 10^{3} & 10^{4}\end{array}$ $\begin{array}{llllll}\text { Recovery } R / \% & 60 & 33 & 13 & 5 & 2\end{array}$

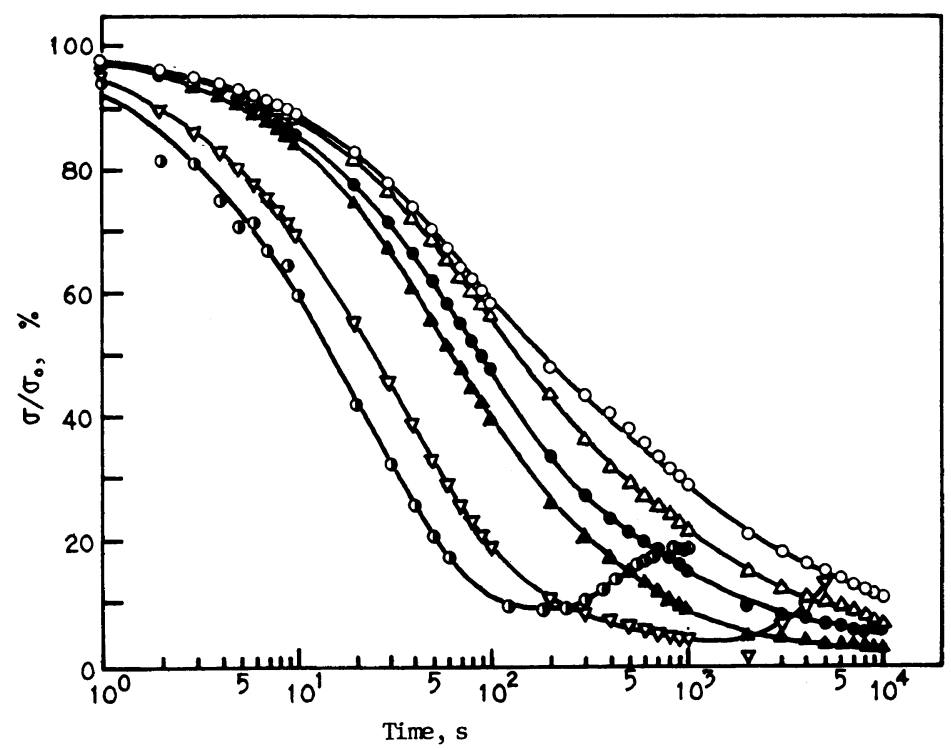

Figure 3. Stress relaxation curves of oriented amor phous PET films drawn at $33 \% \min ^{-1}$ to $\lambda=1.7$ and relaxed at various temperatures. $\bigcirc, 82^{\circ} \mathrm{C} ; \triangle, 85^{\circ} \mathrm{C} ; 0,90^{\circ} \mathrm{C} ; \Delta, 97^{\circ} \mathrm{C} ; \nabla, 105^{\circ} \mathrm{C} ; 0,112^{\circ} \mathrm{C}$. 
served in isothermal crystallization we believe that the induction period corresponds to the stress decay period in thermal relaxation.

In hot drawing of PET film the deformation process leading to chain orientation in global sense is mainly rubbery deformation with small contribution from rubbery flow as shown by $75 \%$ recovery in thermal shrinkage. ${ }^{7}$ Thermal shrinkage at $80^{\circ} \mathrm{C}$ for $1 \mathrm{~h}$ for the above mentioned drawn specimens relaxed at $96^{\circ} \mathrm{C}$ to various times and then air quenched is shown in Table IV. In this case the film remained amorphous after $10^{4} \mathrm{~s}$ of thermal relaxation. As the stress was decaying all the time, the decrease of recovery of deformation during the stress relaxation experiment must be attributed to rubbery flow and chain disentanglement. The fact that in an oriented amorphous film the chain crystallization is to be preceded by rubbery flow and disentanglement is quite understandable. A decrease of chain orientation as revealed by optical birefringence in the initial stage of crystallization at $95-115^{\circ} \mathrm{C}$ of amorphous preoriented PET fiber sample melt spun at $1250 \mathrm{~m} \mathrm{~min}^{-1}$ was also observed by Wasiak et $a l .{ }^{11,12}$
Acknowledgement. This work was supported by Science foundation, Academia Sinica.

\section{REFERENCES}

1. J. He, Ph.D. Dissertation, Institute of Chemistry, Academia Sinica, Beijing, 1985.

2. G. Le Bourvellec, L. Monnerie, and J. P. Jarry, Polymer, 27, 856 (1986).

3. H. J. Biangardi and H. G. Zachmann, Prog. Colloid Polym. Sci., 62, 71 (1977).

4. G. Hinrichsen, H. G. Adam, H. Krebs, and H. Springer, Colloid Polym. Sci., 258, 232 (1980).

5. Z. Qi, J. Guan, J. Shen, and R. Qian, Proceedings of China-US Bilateral Symposium on Polymer Chemistry and Physics, Beijing, 1979, Science Press, Beijing, 1981, p 213.

6. J. Shen, T. Wang, Z. Qi, and R. Qian, Polym. Commun. (China), 81 (1981).

7. R. Qian, J. Shen, and L. Zhu, Makromol. Chem., Rapid Commun., 2, 499 (1981).

8. D. Shen and X. Yang, Spectros. Spect. Anal. (China), 5(4), 19 (1985).

9. D. Shen, X. Yang, S. Zhu, Q. Wu, and Z. Wen, Polym. Commun. (China), 209 (1980).

10. Z. Xu and S. Chen, Polym. Commun. (China), 129 (1979).

11. G. C. Alfonso, M. P. Verdona, and A. Wasiak, Polymer, 19, 711 (1978).

12. A. Wasiak, Colloid Polym. Sci., 259, 135 (1981). 